\title{
Do Recently Diagnosed Black Breast Cancer Patients Find Questions About Cancer Fatalism Acceptable? A Preliminary Report
}

\author{
Vanessa B. Sheppard, Kimberly Davis, Mare Boisvert, Yvonne Jennings, and Becky \\ Montalvo, Journal of Cancer Education, 2010
}

Barbara D. Powe

Published online: 30 September 2010

(C) Springer 2010

The authors address an important area in terms of attitudes and beliefs that may influence treatment decisions among newly diagnosed African American breast cancer (patients) survivors. The authors support previous researchers by pointing out the fact that research on the construct of cancer fatalism among persons diagnosed with cancer is sparse, as much of the research on this topic has focused on noncancer participants and the influence of cancer fatalism on screening behaviors [1-10]. Findings from this study raise the question of whether the philosophical underpinnings of fatalism, as it relates to screening, change or are perhaps different once an individual becomes a survivor. It has been shown that perceptions of cancer fatalism are not an "all or none phenomenon" and in fact, it may be the strength of these perceptions that influenced screening behaviors as opposed to their presence or absence [8].

Philosophically, it seems that once an individual is diagnosed with cancer and becomes a survivor, the belief that "death from cancer is inevitable" could be perceived differently and the influence of these perceptions on treatment decisions needs to be evaluated from that perspective. In fact, survivors were asked about their views about cancer fatalism before their diagnosis and these responses were compared to their current perceptions about

B. D. Powe $(\bowtie)$

Cancer Communication Science, American Cancer Society,

National Home Office,

Atlanta, GA, USA

e-mail: Barbara.Powe@cancer.org cancer. These survivors showed a significant decrease in fatalistic perceptions about cancer [11]. However, these survivors were on average, five or more years postdiagnosis and perceptions about treatment decisions based on these beliefs were not assessed.

As we move forward with these types of discussions, I think we must ensure we are comparing the same phenomena. It may be premature to use the same definitions and instruments (modified) to categorize fatalism for newly diagnosed survivors and then suggest these perceptions influence their cancer-related treatment decisions prior to these types of philosophical inquiries. More research is needed to understand not only attitudes and beliefs, including fatalism, among survivors, but more importantly, potential interactions of these types of variables, their influence on treatments, and their role in the survivorship experience for African Americans. I look forward to additional findings from these researchers on the development of specific measures of "fatalism specific to treatment" and whether these types of attitudes and beliefs coupled with other variable help us understand how to retain African American women in treatment. In addition, it will be important to note whether fatalism about treatment varies by age, stage of disease, and length of survivorship and lastly, whether these types of perceptions vary in those that treatment adherence or follow-up rates. Clearly, the goal is to understand factors that influence the cancer experience for African American women so that we can develop interventions to help them address any unmet needs. I applaud these authors for their continued work in this important area. 


\section{References}

1. Chavez LR, Mishra SI, Hubbell FA, Valdez RB (1997) The influence of fatalism on self-reported use of Papanicolaou smears. Am J Prev Med 13(6):418-424

2. Conrad M, Brown P, Conrad M (1996) Fatalism and breast cancer in black women. Ann Intern Med 125(11):941-942

3. Davis SN, Thompson H, Gutierrez YE, Boateng SG, Jandorf L (2002) Breast cancer fatalism: ethnic differences and association with cancer screening. Ann Epidemiol 12(7):491-492

4. Hall AG, Khoury AJ, Lopez ED, Lisovicz N, Avis-Williams A, Mitra A (2008) Breast cancer fatalism: the role of women's perceptions on the healthcare system. J Health Care Poor Underserved 19(4):1321-1335

5. Hunter A, Parker V (2003) Fatalism toward breast cancer among the women of Ghana. Health Care Women Int 24:608616
6. Mayo RM, Ureda JR, Parker VG (2001) Importance of fatalism in understanding mammography screening in rural elderly women. $\mathrm{J}$ Women Aging 13(1):57-72

7. Peek ME, Sayad JV, Markwardt R (2008) Fear, fatalism and breast cancer screening in low-income African American women: the role of clinicians and the healthcare system. J Gen Intern Med 23 (11):1847-1853

8. Powe BD, Johnson A (1995) Fatalism as a barrier to cancer screening among African Americans: philosophical perspectives. J Relig Health 34(2):119-125

9. Powe BD, Finnie R (2003) Cancer fatalism: the state of the science. Cancer Nurs 26(6):454-467

10. Spurlock WR, Cullins LS (2006) Cancer fatalism and breast cancer screening in African American women. ABNF J 17(1):38-43

11. Powe BD, Hancock N, Hamilton J, Johnson N, Brooks P, Wilkerson D (2006) Perceptions of cancer fatalism before and after a diagnosis of breast cancer: do they change? O. UICC World Cancer Congress, Washington, DC. 7-9-2006. Ref Type: Unpublished Work 